Jack Wilson*

Department of English and Creative Writing, School of Arts and Media, University of Salford

j.j.wilson@salford.ac.uk

*corresponding author

Hazel Price

Department of Linguistics and Modern Languages, School of Music, Humanities and Media, University of Huddersfield

h.price@hud.ac.uk

\title{
Courtroom data and politeness research: A case for neo-Peircean semiotics in
} interpersonal pragmatics

\section{Size: 69,065}

\section{Abstract}

In this article, we take a neo-Peircean semiotic approach to analyzing an interaction in which a routine bail hearing between a defendant and a judge goes awry. Neo-Peircean semiotics is steadily gaining recognition within linguistics for providing a new perspective on meaning. One neo-Peircean approach, referred to as Relationship Thinking (Enfield, 2009; 2013), has the potential to be influential for politeness research and linguistic pragmatics generally. In this article, we explore how the concept of relationship can be used to explore meaning on two dimensions: residential and representational (Kockelman, 2006a;b). It is our contention that both of these dimensions are crucial to developing an understanding of what happens in the courtroom data on which this special issue focusses. We begin by providing a detailed 
overview of neo-Peircean semiotics in order to demonstrate its utility for researchers from different disciplines. We then show how a neo-Peircean analytical approach can illuminate elements of data that may not be accounted for in other analyses. This is as a consequence of the neo-Peircean framework's scope and its capacity for coping with a range of interactionally significant phenomena, from individual linguistic tokens to institutional norms. In our analysis of the data at the heart of this special issue, the Penelope Soto case, we show that problems can arise when interactants have different understandings of what is a sign and what is an interpretant (Peirce, 1955). We make the case that it is a misunderstanding at this level (specifically the interpretations of the word "value") that is ultimately what causes the interaction to conclude in the way that it does. Ultimately, we suggest that a neo-Peircean approach to the study of in/appropriate behaviour can facilitate links between the traditional (and sometimes disparate) methods of analysis used in politeness research.

Keywords: Agency, In/appropriateness, Indexicality, Intentionality, neo-Peircean semiotics

\section{Introduction}

This paper offers an alternative way to analyze and model social interaction. As noted by Bom and Grainger (2015, see also Grainger, 2011), there have been three distinct waves of politeness research. First wave politeness research built on traditional Gricean notions of meaning $(1957,1975)$ and Austinian Speech Acts (1962), focussing on the 'speaker' and the intentional nature of communicative behaviours. Spearheaded by the influential work of Brown and Levinson (1987) this approach was successful in systematizing key aspects of Goffman's work on Face and Facework (cf. 1967). In response to this, the second wave of politeness focussed on the discursive achievement of behaviour with a particular focus on 
emergent properties found in participant evaluations of behaviour (Locher and Watts, 2005). This perspective not only reduced the necessity to theorize about speaker mental states or describe 'model persons'(Brown and Levinson, 1987; see also McIntyre and Bousfield, 2017: 764), but also reduced the impact of the analyst in evaluating (im-)polite behaviour (Locher and Watts, 2005). These two views are quite often polarized, giving rise to two distinct approaches to politeness research sometimes referred to as first-order (i.e., discursive) and second-order (i.e., intentionalistic). More recently a third wave has emerged which explores politeness from an interactional perspective, borrowing methodological apparatus from conversation analysis. A key feature of this approach is to explore the ways in which evaluations of (im-)politeness analyzable of either interactant, but are co-constituted in the interaction itself (cf. Arundale, 2010; Haugh, 2007).

In this paper, we argue that it is possible to model the differing perspectives of politeness using a single semiotic approach, such as Relationship Thinking (Enfield, 2009; 2013). Semiotic models are general because the labels adopted are relevant to a broad range of human (and non-human) behaviours and they are inclusive because they have the potential to be applied to anything that an analyst deems relevant for the perspective they adopt when analyzing the data.

Before beginning our discussion of a relationship thinking approach, it is worth taking a second to point out what we are going to analyze in terms of politeness. Here we are exploring the situational appropriateness and/or inappropriateness of the various behaviours of the interactants in the courtroom data upon which this special issue focusses. We follow Schneider (2012) who draws a parallel between the distinctions of appropriateness and inappropriateness with Watts' (2005) distinction between politic and non-politic. In this sense, what we define as inappropriate is behaviour that is always marked. One of the things we explore is the different ways in which a behaviour can be said to be marked. However, it 
is not our intention in this paper to make the stronger claim that appropriateness equates to politeness (cf. Meier, 1995).

Relationship thinking is an approach to interaction with its roots in old ways of conceptualizing meaning making (cf. Peirce, 1955). Relationships are phenomena involving at least two things (often individuals) that are contextualized by a third entity (the relationship itself). For example, the relationship of the particular defendant and the particular judge in the courtroom data that forms the basis of this special issue is based on an institutionalized notion of their particular statuses within the situation. Here, we follow Enfield $(2009 ; 2013)$ in using status in the sense of Linton (1936) to describe sets of rights and duties with respect to specific others. The statuses involved in the court data can be termed emblematic because they are ascribed by the institution of law and the court (i.e., judge and defendant). Further, it is possible to describe a broad spectrum of statuses. For example, if Ralph is Emma's brother, then Emma is Ralph's sister and together they are siblings. The relationship of being siblings contextualizes both Ralph as brother and Emma as sister. Without it, neither of them could possess either status. It is the relationship of being siblings that governs the way in which they stand in relation to each other. When conceptualized in this way, it is possible to analyze linguistic meaning as a relationship between two individuals and a third element. For example, if Ralph uses the word "coriander" and Emma understands the word "coriander" as Ralph uses it, then they must share (at least partially) the meaning of the word "coriander". However, if Emma was American, she may very well have access to the referent of "coriander" (i.e., a herb often used in Asian cooking), but she may not have access to the particular relationship that Ralph is attempting to invoke, instead having "cilantro" as her sign for that referent. Ultimately, the token relationship that is enacted (e.g., symbolic word meaning, or siblings) relates to a type of relationship that may be invoked across multiple enactments. 
The key distinction is that the second type of relationship (conventional word meaning) is what might be referred to as a representational relationship (Kockelman, 2006a) whereas the first (siblings) might be called a residential relationship (Kockelman, 2006b). Representational relationships are, broadly speaking, about intentionality or how representations (e.g., sentences, thoughts) can be directed or about the world. They are propositional. Residential relationships, as Kockelman suggests (2006b: 20), involve nonpropositional meaning such as "undertaking actions, performing roles, and filling identities". For example, Ralph may perform in a way that indexes his relationship to Emma (as Emma's brother) which would also index her relationship to him (as his sister).

Indexes, in this sense, relate to statuses as a set of rights and duties, based, for example, on the type sibling, and we, as analysts or participants, would be able to contextualize Ralph's behaviour in relation to those rights and duties. Therefore, a status is not something that one has, but something that affords and constrains the potential actions one might undertake at any time. At the most basic interactional level, the status ascribed to an interactant is typically that of speaker or hearer. It is important to acknowledge that the status of an interactant at any moment in time is at least partially determined by the speech act they are producing. For example, if one interactant is a question-asker, then the other becomes a question-answerer. There is a residential relationship that contextualizes the relationship between question-answerer and question-asker, but also a representational relationship that contextualizes the relation between question and answer. From this it is possible to argue that every speech act simultaneously involves engagement in two processes. The first relates to a residential relationship. The second relates to a representational relationship. 
The courtroom data, we believe, represents an example of how both are crucial for the management of successful interaction. An example of this can be seen below in an extract of the data, taken from lines 4-5:

j: $\quad{ }^{o}$ pene ${ }^{\circ}$ [lope so:

d: $\quad$ [yes

Here, in order to understand this two-turn exchange, we must acknowledge that the Judge's turn involves both a summons for the defendant to acknowledge that she is indeed the person who "Penelope Soto" refers to, and an enactment of the status of summoner. The defendant's response contextualizes the Judge's turn as a summons by producing what might be called a summons-response, but also enacts the status of summoned. On the residential side, both of these statuses (summoner and summoned) are embedded within the institutional status of judge and defendant. In fact, the relationship of judge and defendant provides an explanation of why each participant is enacting the status they are. It would be marked for the defendant to summon the judge. What should be clear is that at a basic level, the rights and duties of interactants is largely reflexive. For example, there is an assumption that someone who performs an action has a right to perform that action (however, this may be negotiated interactionally). These statuses may be embedded under higher-order residential statuses that provide additional reasons for the actions. In other words, the projects we are involved in are often embedded in other projects and it is this embedding that provides explanations for basic level moves. This can be delineated as follows:

1. The Judge produced a summons

2. Because he has a right to produce a summons (as a summoner)

3. Because he has a right to be a summoner (as a Judge)

1. The defendant produced a summons-response

2. Because she has a duty to produce a summons-response (as summoned) 
3. Because she has a duty to be a summoned ${ }^{1}$ (as a defendant)

So far, what we have tried to show is how a relationship thinking approach can be used to build a model of both the representational and residential relationships enacted and invoked in the court data from the ground up. In this paper we have two aims: to introduce neoPeircean semiotics and to use it to model one aspect of why the courtroom interaction goes awry. In the next section, we provide a fairly comprehensive introduction to neo-Peircean semiotics. In section three, we use key aspects of this framework to analyze the data. Last, in section four, we draw some conclusions based on our analysis.

\section{What is neo-Peircean semiotics?}

Most scholars working within politeness research will have encountered semiotics in some form or another (indexicality, for example, has been a particularly useful concept in sociolinguistics [Ochs, 1996; Silverstein, 2003;] and politeness theory [Christie, this volume]). Semiotics, broadly speaking, is the study of signs and the operationalization of signs or semiosis (Kockelman, 2005). Within semiotics two approaches have prevailed. ${ }^{2}$ First, the Saussurean approach, originally referred to as semiology, focusses on a binary relationship between a signifier and a signified. Phrased within these terms, semiology is the study of why one thing (e.g., a word) stands for something else (e.g., an object). So for example, when the judge says "Penelope Soto", he is using the proper nouns "Penelope" and "Soto" to refer to the defendant. This works because the two words stand-for the individual whose name is Penelope Soto, who in this interaction is the defendant. If we stopped there,

\footnotetext{
${ }^{1}$ Here "summoned" is not being used as a verb but as a shorthard for 'person being summoned'. In other words, it refers to a membership category and not an action.

${ }^{2}$ Here we only outline the basics of these two distinct approaches, but advise interested readers to the work of Parret (1984) and Kockelman (2005), both of which provide illuminating insights into their history.
} 
then we would have the basis for a referential theory of meaning based on what Kockelman (2005) would call a relationship of standing-for.

The second approach, originally referred to as semiotics, was conceived by Peirce (1955). However, Peirce's contribution to the field of semiotics is often treated as an enrichment of the Saussurean view, keeping the relationship of standing-for and subdividing it into three types (or grounds). These are iconic, indexical, and symbolic. Iconicity is defined as a relationship of similarity and, as such, a drawing might be described as an icon of what it represents. Indexicality is a relationship of contiguity, such that there is a genuine "realworld" connection between signifier and signified. A common example is pointing, because it is the vector created by the signifier that affords the relationship between it and the signified. A test of indexicality is that the signifier is affected by the signified. In this sense, a point does not refer to anything, it is only once the object being pointed at is located that the meaning of the point is fixed. Symbols are based on conventional (often arbitrary) relationships between signifiers and signifieds. Words (e.g., "dog", "coriander") are the classic examples of symbols, because without knowledge of their relationship they cannot be used to refer. Most contemporary approaches to semiotics assume that these grounds do not work exclusively, but some elements of all three are commonly invoked in each relationship between signifiers and signifieds (cf. Enfield, 2009). For example, the word "she" is both symbolic (in the sense that it conventionally refers to females) and indexical (because it only refers once a specific referent has been assigned).

The enriched Saussurean view of meaning not only fails to do justice to Peirce's framework, it cannot completely capture what is happening during semiosis. For example, in the case described above, the judge is not simply referring to the defendant; the reference only forms part of the judge's purpose in uttering those words. A neo-Peircean approach incorporates the notion of standing-for but establishes it within a more general notion of 
correspondence (Kockelman, 2005). To do this, neo-Peircean scholars adopt a third element in the relationship of a signifier and signified (hereafter, sign and object ${ }^{3}$ ), which is known as the interpretant. The interpretant is whatever is produced as a result of a sign standing for a referent.

The semiotic relationship between this meaning triad is represented visually in figure 1. However, it is not simply the case that the interpretant is added to the sign and object, all three are necessary components of meaning. Therefore, meaning rests not in the fact that a sign stands for its object, but rather that there is a correspondence between the relationship of sign and object and of the object and interpretant. It is this notion of correspondence that marks neo-Peircean semiotics as 'relationship thinking'. From this perspective, objects are not necessarily things in the world (although they may be things in the world) or mental representations (although they may be mentally represented), but rather correspondencepreserving projections. This correspondence is the object of that sign.

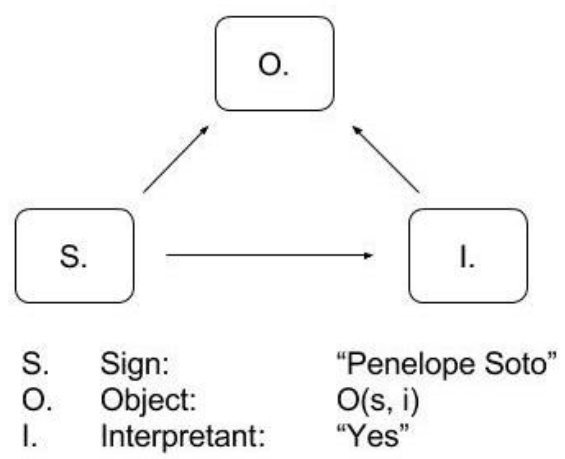

Figure 1.

\footnotetext{
${ }^{3}$ As we will show below, the Peircean notion of object is not identical to the Saussurean notion of signified, but they are similar enough for the comparison at this point.
} 
In figure 1, the object "O" represents a correspondence between the sign "Penelope Soto" and its interpretant "yes". In this paper we adopt the convention of representing the relationship between objects, signs and interpretants as object(sign, interpretant) or $O(s, i)$. In this example, the object is an abstraction from these two behaviours, based on the assumption that they are paired. Furthermore, in this case, the sign and interpretant are temporally contiguous, but, as we will argue below, this is not necessarily the case.

\subsection{Interpretants}

As described above, the relationship between a sign and object, or ground, comes in three (non-exclusive) forms. For interpretants, there are at least four types (Kockelman, 2005). First, an energetic interpretant is a type of action. An example of an energetic interpretant is an individual passing a book in response to the request "could you pass me that book?". Second, affective interpretants are uncontrolled feelings or sensations. Blushing, for example, is an example of an affective interpretant. Third, representational interpretants are symbolic. For example, the defendant's "yes" is a representational interpretant. Finally, ultimate interpretants are private, cognitive responses. For example, the defendant may mentally represent something as a response to the judge that is never realized as part of an affective, energetic, or representational interpretant. That is not to say that something which is realized representationally, for example, is not also realized ultimately. In fact, it is part of many theories of linguistic meaning that an utterance is a realization of some underlying, mentally (but not necessarily consciously) represented propositional content (cf. Carston, 2002).

The key thing to recognize is that almost all of the interpretants that we encounter as human interactants are not ultimate interpretants and none of those that we can analyze as analysts of interaction are. As analysts, what we have access to are affective, energetic, or 
representational interpretants. However, because a semiotic model is able to capture different interpretant types, ranging from private and cognitive responses to unintentional behavioural responses, we are able to capture data and also build theoretical models of the cognitive processes involved in semiosis using a largely unchanged framework. Focussing on different types of interpretants has given rise to different disciplines within linguistics. For example, Archer and Lansley's work (2015), which builds on Ekman's (1999) studies of microgestures, explores how such gestures relate to mental states. Such micro-gestures are affective interpretants of those mental states. Much of the psycholinguistic literature explores the behavioural reaction to linguistic stimuli (e.g., selecting objects or neuronal reactions), which are energetic interpretants. Last, most of the discursive approaches to language, conversation analysis being the paradigm example, explore symbolic responses to symbolic behaviour.

Such symbolic responses are representational interpretants.

\subsection{Objects}

Above, we said that objects are about correspondence. Within linguistics, we often think of objects as being fairly objective (Kockelman, 2005: 242). In other words, objects are the stable thing to which the dynamic word refers. When we talk of language change, it is the language that is changing and not the objects to which language refers. The neo-Peircean framework adopted here requires that the object cannot be completely considered outside of the use of a sign and a resultant interpretant. Therefore, objects, in a single instance of semiosis, are not objective, but rather determined in situ. Additionally, just as we typically think of words as existing in a relationship of types and tokens, objects can also be thought of in this way. A symbolic ground is a projection from a sign to a particular object, which considered abstractly are both types. For example, the word "coriander" is type of sign which maps onto a type of object. Further, if used referentially, a tokening of the word "coriander" 
can map onto the real-world plant as a token object. As we will see below, this distinction affords the analysis of types of residential relationships, such as sibling, or tokens of residential relationships such as siblings(Ralph, Emma). In short, objects are the glue that holds semiotic behaviours (in the form of signs and interpretants) together.

\subsection{Interaction as projects: building up from the bottom}

Several tasks must be completed in order to complete the higher-order task of the bail hearing. Various literature in pragmatics has dealt with this idea and we will make use of existing terminology to explain these different levels of tasks. From Clark (1996) we use the notion of projects and the relative terms sub-projects and minimal sub-projects, e.g., before completing her bail hearing, it is necessary that the defendant completes the sub-project of disclosing whether or not she can afford to pay for her own legal representation. Depending on the level of abstraction of the object of study, sub-projects can be canonical adjacency pairs such as a question/answer sequence (if it were part of achieving a bigger goal of a project) or, if the question/answer exchange completes the project, then it would be a project in itself.

While the higher-order project provides context for the interaction, the interaction also provides structure for the project. It is the rules of conversation (e.g., turn taking) that determine the basic level structure of the project. At the most basic level, each two-turn sequence, consisting of a presentation phase (e.g., question) and acceptance phase (e.g., answer), are considered as basic projects, but these may be embedded within higher-order projects which are indexed by particular moves (Clark, 1996: 227). For example, the summons sub-project is embedded within the court hearing project. It is important to recognize that for a sub-project to be properly considered within a higher-order project, the 
rules of the higher-order project are crucial to the sub-project. In other words, there is no condition on who is the summoner and who is the summoned for the summons sub-project, but the courtroom project comes with rules that stipulate that the individual acting under the status of court official will be the summoner and the individual acting as the defendant will be the summoned.

Projects help link representational and residential relationships to key features of human cognition, which are not necessary for a general model of semiosis, but are crucial to our understanding of human semiotic processes. One of these features is discussed in the next section as agency.

\subsubsection{Agency}

Agency may be thought of as the enactment of certain means to achieve certain ends. We ascribe a greater degree of agency to an individual who has more choice in the means open to them (Kockelman, 2007). Generally, there is an assumption that an individual employing certain means did so because they are able to predict how well those means will produce the ends they are hoping for. This form of prediction, Enfield (2013: 31) refers to as subprehension. For example, an individual who chooses to take a lift instead of the stairs (means) might have done so because it is an easier way to reach their destination (ends). This evaluation of the relative ease of taking the lift is a subprehension. During interaction, an individual who produces a sign typically does so subprehending the interpretant that will result. Therefore, in our analysis we use the term agency to describe a sign producer's presumption that the production of a certain sign will result in a certain interpretant. In other words, if a sign producer produced the sign "would you like some tea" they may expect that a "yes/no" response will follow. 
There is a presumption that a sign is produced with a purpose, and that purpose (for the analyst) is realized by how it is interpreted. This captures the residential nature of meaning at a basic level. Further, the sign also has a representational content (which it has irrespective of the purpose of the agent) and this representational content is also realized by the interpretant. As we will see, the further we go from the basic level of semiosis, the greater the difference between these two dimensions (residential and representational) become.

However, it is crucial that as analysts we never lose sight of the fact that both are inherently relevant to interaction.

With these two features in place, we can enrich the model presented in figure 1 . The new model is presented in figure 2 :

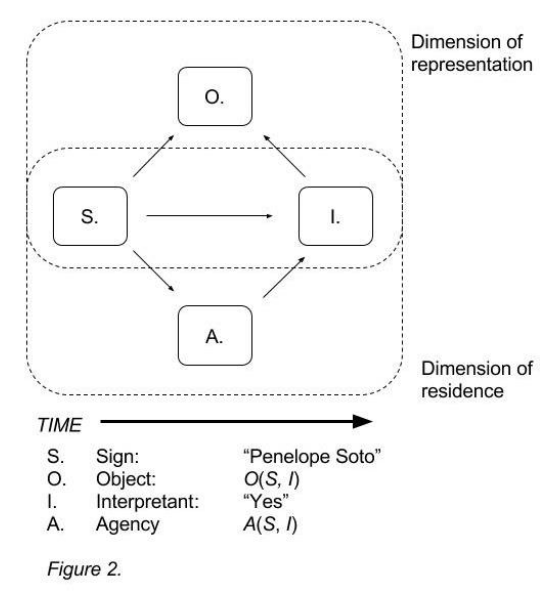

Figure 2 attempts to capture the fact that the Judge produced $S$ with the expectation that the defendant, upon recognizing $S \rightarrow O$, would produce $I$. In other words, the interpretant "yes" is a predictable response to the sign "Penelope Soto". Therefore, on the assumption that the judge is in control of his behaviour and aware of the context in which he performs it, he is aware of his behaviour's appropriateness and expects his behaviour to produce a certain response. Agency then, like the object, preserves the correspondence between sign and 
interpretant. In this case, agency is the enactment of the statuses of summoner and summoned.

This consideration of agency in interaction is what sets neo-Peircean analyses apart from typical conversation analytic analyses.

Once in place, the model of semiosis in figure 2 can be subject to two key processes that illuminate situated interaction (like that of interest in politeness research specifically) without ignoring the fundamental nature of individual examples of semiosis. These processes are referred to as chaining and embedding (Kockelman, 2012) and each will be covered in turn using examples from the Soto data.

\subsubsection{Chaining}

During semiosis, most interpretants are also signs in other semiotic processes, this is no less true during interaction. Sequences of semiosis are taken as paired behaviours. In Conversation Analysis such pairs are regularly called adjacency pairs or, under Clark and Krych's (2004) notation that aims to capture non-verbal behaviour, projective pairs. The use of the word projective has two meanings. First, both elements (e.g., turns) are considered to be part of the same (joint) project. Second, the first pair-part in the project projects a suitable second pair-part. This projection is the object (or correspondence preserving projection) that maps the relationship between the first pair-part and the second pair-part. ${ }^{4}$ During the turn taking of conversation, each turn is taken as an interpretant of a previous turn (which is a sign) and as a sign for the following turn (which is its interpretant). For example, during the interaction the following sequence (lines 166-174) can be observed:

j bye? bye,

d adi:?o:s.

${ }^{4}$ This second meaning relates to what is commonly referred to as preference organisation within conversation analysis (Hutchby and Wooffitt, 2008: 46; Pomerantz, 1984; Sacks, 1987). 
j ohehehehe ${ }^{\circ}$ COME $\underline{B A C K}$ MAM.

In this sequence the judge utters the fairly quotidian "bye bye" as a form of closing,

additionally waving at the defendant. In response, the defendant says "adios", equally

commonplace as a farewell in certain contexts. These two utterances, in many contexts would seem perfectly acceptable: "adios" is a type conforming response to "bye bye". However, the judge's next turn shows that the defendant's utterance was problematic in this context. We can analyze this using the semiotic framework proposed here as follows:
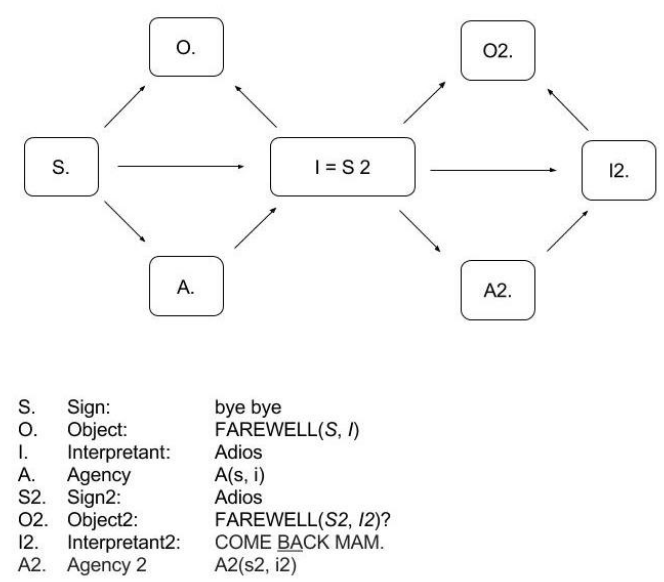

Figure 3.

In this case, the first sign is the judge's utterance of "bye bye". Symbolically "bye bye" is a sign of farewell. The judge's utterance is projecting an object that might be thought of as representing FAREWELL ${ }^{5}$ or CLOSING. The object of the first sign is realized by the defendant producing an appropriate next turn: FAREWELLs usually produce FAREWELLs. Therefore, this interpretant completes the first semiotic process in this sequence. The object

${ }^{5}$ In the analysis capitalisation is used to represent the abstract labelling of sequences. 
that preserves the correspondence between the judge's turn and the defendant's response is labelled as FAREWELL $(s, i)$ since both 'bye bye' and 'adios' both correspond to the projection created by the sign which pairs these as elements in a farewell sequence. The interpretant is also a sign, which is labelled as sign2. If sign2 was produced as the end of the FAREWELL sequence then we would expect the interpretant to realize it as such by marking a shift either by introducing a new topic (which would be unexpected since the FAREWELL sequence closed the interaction), by issuing another sign of farewell, or by beginning an interaction with another individual. However, none of these things happen in the interaction. The interpretant that follows sign2 is labelled as interpretant2. Sign2, equally (simply taking its symbolic linguistic properties into account) projects FAREWELL as its object (O2). However, interpretant 2 is such that the projected object is not correspondence preserving. In other words, the judge's response suggests that the defendant's farewell is inappropriate. This is marked with "?" in figure 3. The first interpretant is type conforming whereas the second interpretant is non type conforming. This is not to say that $\mathrm{O} 2(s 2, i 2)$ is less of a semiotic process than $\mathrm{O}(s, i)$, it is just that $\mathrm{O}(s, i)$ can be understood rather straightforwardly (as a token of a particular type of sequence) whereas $\mathrm{O} 2(s 2, i 2)$ requires an interpretation of its particularity (as a token without a type).

Turning to the dimension of residence, agency is represented as A and A2. Here A would represent the correspondence between the judge (as the producer of S) and the defendant (as the producer as I) in terms of their duties and rights. Since agency is based on the idea that an agent is in control of their own behaviour and able to subprehend the interpretant it will produce, we must assume that the production of interpretant 2 (' $\mathrm{COME}$ BACK MAM'), suggests that there are additional features to sign2 that were not subprehended by the defendant.

This can be explored in more detail by considering the next semiotic process of embedding. 


\subsubsection{Embedding}

Embedding captures the fact that most objects can be taken as either signs or interpretants in higher-order semiotic processes.
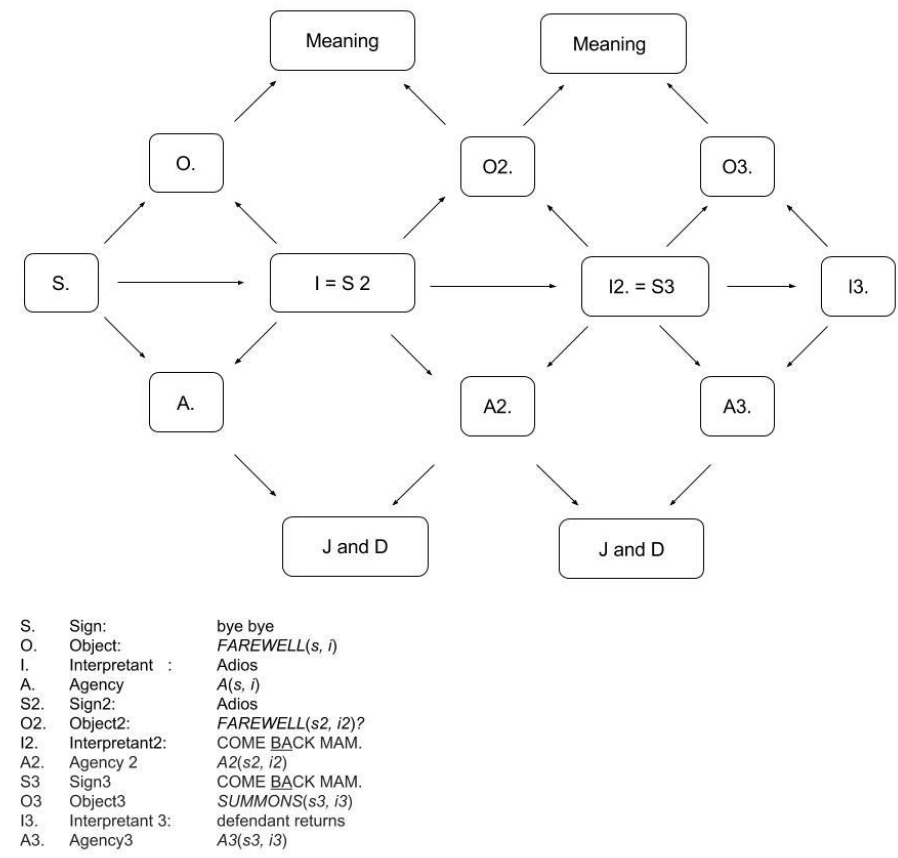

\section{Figure 4.}

This model captures the interaction at three levels. At the basic level are the behaviours themselves. This level is supposed to capture the qualities that make up the behaviours, which are not being treated as semiotic. However, it is important to stress that the analyst necessarily has to choose which behaviours are represented at this basic level and that process 
is a form of analysis ${ }^{6}$. The next level, which we have been describing in terms of objects and agency is one level of abstraction. Here, as analysts we are positing correspondences between two behaviours, attempting to reconstruct their semiotic properties in accordance with both representational and residential structures. At this second level, these correspondences are emergent through behaviours. The second level of abstraction represents meaning on the representational dimension and situation-specific statuses (judge and defendant) as opposed to interaction-specific statuses (farewell-initiator and farewell-responder). As we now show, this level can be used to represent token behaviours as instances of types and the structure of discursively-realized higher-order relationships.

Turning first to the representational dimension, typically occurring pairs of communicative behaviour may be considered types (as opposed to tokens) of paired communicative behaviours. A greeting followed by a greeting or a question followed by an answer, to give just a couple of examples, represent canonical types of paired behaviour, whereas a question followed by a farewell does not. This is not to say that such sequences do not occur, but that their occurrence is typically associated with novel (but not certainly not uncommon) interactional sequences. Novel pairings are tokens without types and are sometimes referred to as singularities (Kockelman, 2005: 241). When a behaviour is taken as an instance of a type, each token object is embedded under its type. Since embedding is also a semiotic process, we can conceptualize it as consisting of a sign, object and interpretant. For example, taking the first sign ("bye bye") we can treat the node referred to as "meaning" as its interpretant because the sign is not a one-off occurrence, but an instance of a particular type of sign. Therefore, the object of this process, which is represented as $O$ and

${ }^{6}$ For example, here we are mainly focussing on the linguistic realisations ignoring the fact that many nonlinguistic features are likely to play a role in the interaction (e.g., eye gaze, dress, body posture, etc.) 
FAREWELL is the correspondence between this particular tokening of "bye bye" and what "bye bye" conventionally means. This can be represented as:

\section{FAREWELL(bye-bye, meaning)}

If we stopped here, we would have the abstract notion of the meaning of "bye-bye", constrained by its projection in this particular interaction. However, the node referred to as "meaning" is not only treated as an interpretant but also as an object at a second level of abstraction. This object relates to the correspondence between the two objects at the second level and the three behaviours at the basic level. This is represented as:

meaning(

FAREWELL(bye-bye, adios),

FAREWELL(adios, come back mam)? )

What this level of representation is able to capture is what has been referred to as a grounding sequence (Bavelas et al., 2012). As analysts focussing on the basic level of behaviour we are not able to analyze the judge's intention in producing his utterance of "bye-bye" except to say what it conventionally means. However, by analyzing the interaction at this third level we can capture the relationship between the judge's turn and his reaction to the defendant's response. In other words, this sequence suggests that the judge is not content with the defendant's behaviour because interpretant 2 is not what one would expect following a FAREWELL projecting interpretant to a FAREWELL projecting sign.

This can be explained since the interpretant produced by the defendant ('adios') contextualizes the sign produced by the judge (realized as the object FAREWELL $(s, i)$ ) but also projects a second object which is contextualized by the judge's second turn (interpretant2). At this third level, we should expect that the objects projected by chained semiosis are related. Semiotically, we could represent this as meaning $(o, o 2)$ where the object realized by $s$ and $i$ corresponds to the object realized by a subsequent chained sequence of $s 2$ 
and $i 2$. The purpose of representing the interaction in this way is to capture the fact that the defendant's utterance is informationally fitted to the judge's utterance, invoking an expected projective pair, but the judge's subsequent turn is not, suggesting that the defendant's turn is not appropriate. What this shows is that while each behaviour is a genuine interpretant of each sign, determined as meaningful because of correspondence between the two behaviours, it is not necessarily the case that each correspondence is based on pre-existing relationships between signs and interpretants. We can represent this sequence as follows:

meaning (

\section{FAREWELL(adios, come back mam)? \\ SUMMONS(come back mam, defendant returns) \\ )}

A summons seems like a particularly marked response to a farewell and suggests a breakdown at some level in the interactional sequence.

In the beginning of this article we suggested that a neo-Peircean framework can represent both intentionalistic and discursive perspectives. This is achieved through the two approaches to framing interaction that we have just outlined, first where "meaning" is treated as an interpretant, and second where it is treated as a higher-order object. The "meaning" as interpretant framing reflects an intentionalistic stance, because it is about the relationship between the type of meaning that a token utterance corresponds with. The "meaning" as higher-order object framing reflects the emergent meaning of a particular behaviour over the course of the interaction.

We can make the same observation on the residential dimension. This time we can highlight the relationship between the first sign, agency, and judge and defendant. We assume that the judge produced the first sign, subprehending that it will be interpreted in a certain way. This subprehension, at the level of agency, is based on the judge's rights and duties, not as a judge but as a sign producer. However, the judge is not simply operating as a sign 
producer, but under the emblematic status of judge, which comes with pre-ordained rights and duties. This emblematic status can be treated as an interpretant which relates to his behaviour. We can represent this as:

$$
\text { agency(bye-bye, JandD) }
$$

Conceived this way, the judge's status as a judge is the result of his behaviour. This may seem odd because the judge's status may be thought of as the reason he acts in a certain way. This is down to semiotic framing and there is no reason why we could not reverse the order of elements to be represented as:

agency(JandD, bye-bye)

Conceived this way, we are representing the fact that the judge's behaviour is the result of the fact that he is a judge. The way we order the elements can represent the way that certain statuses are emergent through behaviour while certain behaviours are the product of statuses. For example, someone who behaves in a heroic fashion may be given the status of hero because this status emerges through their behaviour. Whereas, someone with a criminal record may be expected to act in a certain way, not because this status is emergent in their behaviour, but because their status (as someone with a criminal record) is used to interpret their behaviour in a certain way. In most situations, both directions are relevant. The crucial point is that the relationship between the judge's behaviour and his status is based on the idea that their correspondence is determined by his agency.

If we treat the node described as $J$ and $D$ as an object, then it is a correspondence preserving projection between agencyl and agency2. Remembering that agency in this sense is really joint agency, these relate to the judge being able to subprehend how his behaviour will be interpreted and the defendant being able to subprehend how her behaviour will be interpreted according to their mutual emblematic statuses of judge and defendant. Taking the 
three basic-level behaviours, we can interpret the judge's summons as something he has the right to do as a judge because the defendant has behaved in a way that is inconsistent with the way the judge expected her to behave. This shows, once again, that the breakdown of expected behaviours on the representational dimension can be described in terms of expectations on the residential level.

As we further develop these two dimensions, it might seem that we are distancing the dimensions of representation and residence from each other. However, it is important to stress that the only requirement of the neo-Peircean framework we are adopting is that we carefully define each instance of semiosis. The structure we are describing is just one of multiple ways to conceptualize interaction. Also, the fact that residence and representation are seen to be opposite ends of the structure is simply an artefact of our visualization, there is no reason to consider them this way. The final piece of the structure we want to suggest, is what might be called Activity. We use this term in the sense of activity type (Levinson, 1979), which, of course, are realized as activity tokens. Activity can be thought of as preserving the correspondence between $J$ and $D$ and Meaning, which, like other levels of semiosis, can be framed as Activity(jd, meaning) or Activity (meaning, $j d$ ). The first of these frames marks the meaning on the representational dimension as being the product of the residential relationship between the interactants. The second frames the residential relationship between the interactants as emerging from the representational meaning of their behaviours. In other words, we can understand what they mean because of who they are or we can understand who they are because of what they mean. The framing an analyst adopts is largely determined by the perspective he/she chooses to take. What this final point affords the analyst is the ability to consider the implicatures that are dependent on the particular relationship of the participants, rather than simply exploring how the relationship is affected by the meaning of what the participants do representationally. 


\section{Analysis}

So far, we have attempted to make an abstract theory digestible by way of examples taken from the Soto data. In the following analysis we highlight a part of the data which we have not yet discussed, and which has not formed the focus of any of the papers in this special issue (although it is discussed in O'Driscoll, this issue). Neither was it discussed in the media and YouTube comments that were generated in response to the video. The sequence we are analyzing, reproduced below, occurs towards the beginning of the video (lines 35 to 107) while one of the court officials (not the judge) is asking the defendant questions to determine whether or not she is eligible for pre-trial services (PTS). The purpose of the following analysis is to show how a neo-Peircean approach can be used to explore an extended data sequence, illuminating aspects of the data.

Example 2 (lines 35-107)

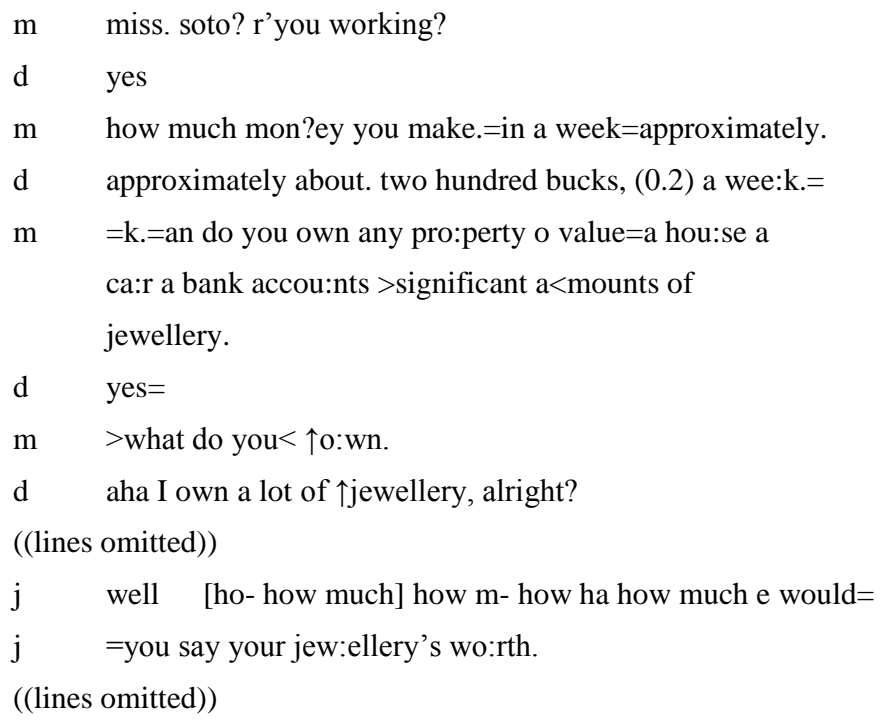




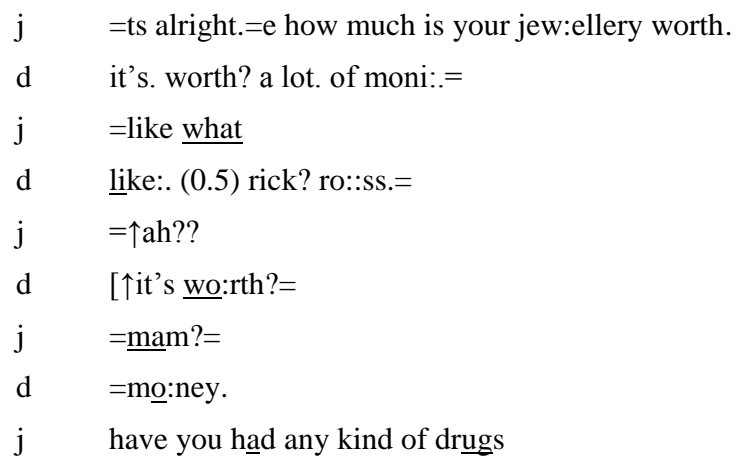

Describing the interaction on the representational dimension, the first question-answer sequence is a yes/no minimal sub-project which can be represented as:

$\mathrm{Y} / \mathrm{N}-\mathrm{Q}($

miss soto are you working, yes

Here, the acceptance phase is fitted and appropriate to the presentation phase, since a yes/no question projects a yes or no response. The next sequence marks a shift in questioning to

WH-QUESTION sequence. Treating the WH-QUESTION as an interpretant to the defendant's "yes" response, we can argue that the court official is moving on with their line of questioning and that the defendant's response was appropriate. This can be represented as:

meaning(

$\mathrm{Y} / \mathrm{N}-\mathrm{Q}$ (miss soto are you working, yes),

Y-RESPONSE(yes, how much money you make in a week approximately) )

The interpretant of the "yes" response builds on the sign of the Y/N-Q and is informationally more specific. In other words, what this response suggests is that the $\mathrm{Y} / \mathrm{N}-\mathrm{Q}$ sequence was a means of initiating this more specific question. Treating the court official's turn as a sign, we can represent the following sequence as: 
WH-Q(

how much money you make in a week approximately,

approximately about 200 bucks a week

)

Once again, the defendant's response is appropriate and fitted. The defendant even mirrors the form of the question reproducing the adverb "approximately". Following this, the court official moves on to his next line of questioning:

\section{WH-Q_RESPONSE(}

approximately about 200 bucks a week,

and do you own any property of value, a house a car a bank account?

)

The interpretant realized by the court official's response marks a move onto the next line of questioning. The meaning of this sequence can represented as:

meaning(

WH-Q(how much money you make in a week approximately?, approximately about 200 bucks a week),

WH-Q_RESPONSE(approximately about 200 bucks a week, and do you own any property of value, a house a car a bank account?)

)

The next sequence mirrors the interactional structure of the first and can be outlined as:

\section{Y/Q-QUESTION(}

and do you own any property of value, a house a car a bank account?,

Yes

)

Y-RESPONSE(

Yes,

what do you own?

)

WH-QUESTION(

what do you own?, 
I own a lot of jewellery alright

)

The structure of the interaction up to this point has been: Y/Q-QUESTION, Y-RESPONSE,

\section{WH-QUESTION, WH-RESPONSE, Y/Q-QUESTION, Y-RESPONSE, WH-QUESTION,}

WH-RESPONSE. The first four elements in this sequence are repeated in the second four

elements. Therefore, framing this interaction representationally, it might seem that the defendant's second WH-RESPONSE will be accepted and the court official might move onto another line of questioning. The defendant seems to be playing her role in the project.

However, minimal projects are embedded within higher-order projects and, as we will see, the interaction does not proceed smoothly. On line 64, the defendant's turn results in a further, more specific WH-QUESTION, this time coming from the judge. Taking the defendant's turn as a sign and the judge's turn as the interpretant, we can represent this sequence as:

\section{INSUFFICIENTREPLY(}

I own a lot of jewellery alright ${ }^{7}$,

well ho how much e would you say your jewelry's worth? )

The interpretant produced by the judge suggests that there is a problem with the defendant's answer to the question. The question breaks the emergent structure of the project, providing evidence that the defendant's turn was not an appropriate move. However, in order to answer why this occurs, we need to analyze the residential dimension and the behavioural games contained therein. The reinterpretation of the first yes/no question-answer sequence from the residential dimension can be represented as:

agency (

\footnotetext{
${ }^{7}$ One reviewer suggested that turn final "alright" can be used to close down a prior speaker's talk thereby securing speakership. This seems to fit with the fact that the judge chooses this moment to enter the conversation. However, if "alright" is functioning in this way it does seem to strengthen the idea that the defendant has not understood the appropriate notion of value since she is closing down this line of questioning (see below).
} 
miss soto are you working?,

yes

)

Here, agency is not attached to a single individual but is the correspondence between the question asker's subprehension (the assumption that the defendant will know why this question is being asked and will have the ability to answer it) and the answerer's (inferred) representation of the reason the question was asked. In other words, a speaker asking a yes/no question is likely to do so expecting that the recipient is going, if able, to produce a yes/no response. Further, the question answerer will infer this subprehension based on the fact that the question asker produced such a question. By moving on to the next question, the question asker provides an indirect acceptance of the defendant's response suggesting that their answer was sufficient:

agency 2(

yes,

how much money you make in a week approximately?

)

This can be interpreted at the level of their statuses as court official and defendant:

Statuses:COandD(

agency1,

agency 2

)

These statuses relate to the court official's right to ask questions of the defendant and the defendant's duty to answer them if possible. Further, because at this level we are treating agency 2 as the interpretant of agency1, agency 2 is treated as being the result of agency 1 where the correspondence between the two is partly determined by the fact that they are embedded within the statuses of court official and defendant. Locally, agency is negotiated, but it is also the result of the top down effect of the participants' respective statuses. By 
moving on in the line of questioning, it signals that both participants are acting according to their respective statuses. Moving onto the next sequence:

agency3(

how much money you make in a week approximately?, approximately about 200 bucks a week

)

In this second sequence, we can make the same claim. With these two sequences in place we can move up the embedded structure to represent the relationship between the court official and the defendant.

Statuses:COandD(

$$
\begin{aligned}
& \text { agency2, } \\
& \text { agency3 } \\
& \text { ) }
\end{aligned}
$$

At this level, properties relating to the rights and duties of the two interactants have a top down effect on the types of agency that might be expected. This is because the statuses enacted in this interaction are fairly emblematic, or, they are symbolic. The defendant's and court official's behaviours are based on types of statuses. In terms of the emblematic status of the court official, this provides the right that they are able to ask personal questions regarding the defendant's financial situation, but also that the defendant has a duty to answer them truthfully. Further, the court official has a duty to provide the defendant with a fair trial, but the defendant has the right to object if they feel they are being treated unfairly. When the interaction continues without issue, it is difficult to examine the ways in which agency and status interact with interactional sequences. This is because it is only when the normative practices constrained by emblematic statutes are challenged that suprehensions and inferences based on those statuses are revealed to be misaligned. 
We believe that it is the next sequence that sows the seeds of this misalignment and, once misaligned, they never align again. Due to spatial limitations, we provide a model that highlights the problematic element.

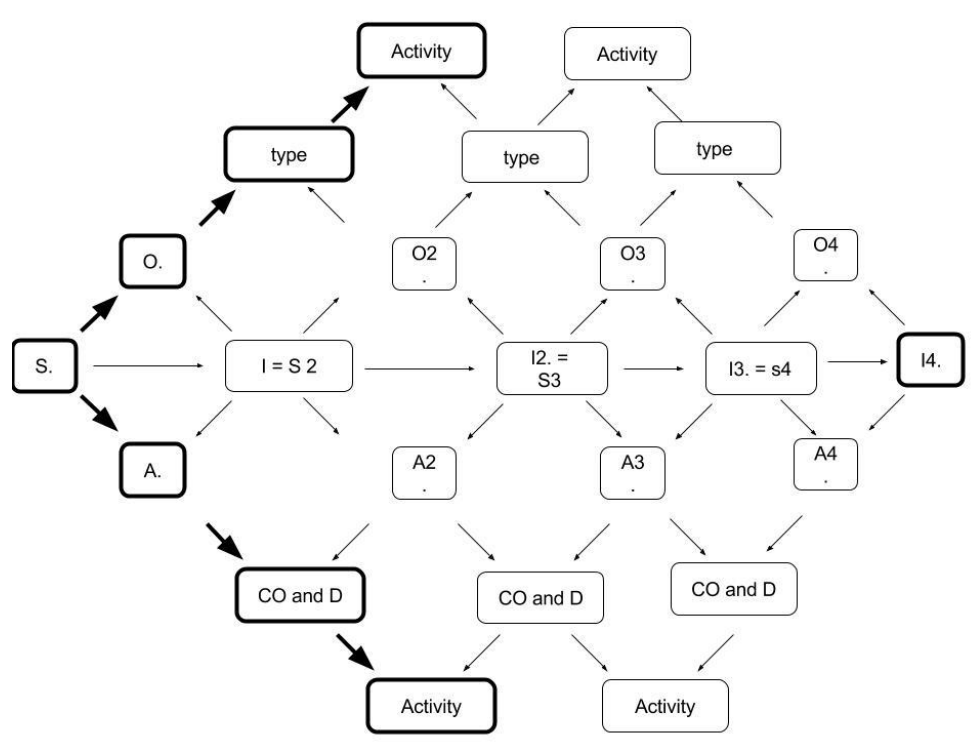

S. Sign: do you own any property of value=a house a car a bank account significant amounts of jewellery

O. Object: $\quad Q-Y / N(Q-Y, R-Y)$

I. Interpretant: Yes

A. Agency: $A(s, i)$

S2. Sign2: Yes

O2. Object2: $\quad R-Y(s 2, i 2)$

I2. Interpretant2: what do you own?

A2. Agency 2: $\quad A 2(s 2, i 2)$

S3 Sign3: what do you own?

O3 Object3 O3(s3,i3) 
I3. Interpretant 3: I own a lot of jewellery alright
A3. Agency3:
A3(s3,i3)
S4 Sign4: I own a lot of jewellery alright

O4 Object4: O4(s4,i4)

I4 Interpretant4: well ho how much would you say your jewellery's worth

Figure 5

The issues highlighted by figure 5 are represented using bold lines. The first is related to the first question "do you own any property of value". However, it is crucial to emphasize that this is not necessarily a problem on the representational dimension, because the object of the two turns is type conforming. The problem here is an implicative enrichment of the word 'value' derived from an interaction between the residential dimension and the representational dimension. That is, from the perspective of the representational dimension, the defendant's response is fitted. However, from the perspective of the residential dimension, the defendant's response does not correspond with her status as defendant. It is because this is an activity based on the participants' statuses as court official and defendant that there is an expectation that the enrichment of the word 'value' will be relevant to both interactants.

We argue that without an institutional context, 'value' is typically perceived in a relative sense. Therefore, value is determined in accordance to the relationship between an individual and an object e.g., a family heirloom

Value(I, o) 
However, value is also often understood as an institutional notion ${ }^{8}$. For example, the value of a $£ 5$ note is determined not by its relation to an individual, but its relation to an institution (in this case the Bank of England).

Value(inst, o)

The argument we want to make is that in the courtroom setting, 'value' is not an individual notion but an institutional one. In this case, one that is determined by the amount of property a defendant must own before they are not eligible for pre-trial services. The speaker's implicature can be glossed as "value of an amount enough to pay for your own legal services". However, because the defendant does not access this implicature (and perhaps does not have access to it), it is not treated according to this more specific meaning. We can represent this as:

\section{Value according to the courtroom activity agency(Statuses:COandD, do you own any property of VALUE*) *value of an amount enough to pay for your own legal services} Value without access to the emblematic statuses relevant to the courtroom activity agency(?, do you own any property of VALUE*) *value of an amount significant to you

In the first of these two representations, we are taking what we believe to be the court official's subprehension of their turn. They are treating 'value' in a particular way and expecting that the defendant will infer this narrowed meaning (Wilson and Carston, 2007). In the second, we are representing the possible inference that the defendant makes. The same claim could be made by the adjective "significant" which modifies the noun phrase "amounts of jewellery". On the assumption that one understood "value" relatively, "significant" would

${ }^{8}$ See Jackendoff (2007) or Searle (2010) for detailed explanations of the difference between individual and institutional values. 
mean something like "significant to you". However, if it is understood institutionally, then "significant' means something like "of significance to one's ability to pay for legal services".

Once we acknowledge this potential for ambiguity, what continues to happen throughout the interaction becomes clear. In the model, the semiotic process initiated by sign3 "what do you own" will project different objects depending on which understanding of 'value' was taken in the court official's previous utterance. If 'value' was enriched by taking into account the courtroom activity, then this question has a very specific answer. The answer would be related to whether or not the value of the defendant's jewellery reached a threshold, above which she would not be eligible for pre-trial services. However, on the alternative (individual) reading of 'value' it is not clear exactly what object might be projected. What we have is how the defendant responded in interpretant3:

Agency3(what do you own, I own a lot of jewellery alright)

Here, the defendant's turn does not relate to any particular value, but uses a vague term of large quantity (i.e., "a lot"). Therefore, while this turn is fitted in terms of the turn design, it is not fitted in terms of agency because this turn is not embedded under the statuses of the two participants. It is inappropriate for the legal setting the defendant is in. Further evidence for this can be found when we consider interpretant 3 as sign 4 . Interpetant 4 is marked because it represents a representational interpretant from someone who, up to this point, had not been involved in the interaction. Further, it is a representationally equivalent utterance to sign3. The big difference being the shift from the word "value" to the word "worth".

Up to this point we have identified what we believe to be the early troubles source and explained why the defendant may not have access to the enrichment of this utterance based

${ }^{9}$ One anonymous reviewer highlighted the fact that out of the objects of value the court official offers as suggestions (i.e., house, car, bank account, jewellery), jewellery is probably most likely to have affective value for the individual. However, the same reviewer also pointed out that by choosing one of the options suggested by the court official (i.e., jewellery) the defendant is, in fact, displaying an understanding of the ques tion. 
on a lack of access to regulatory forces created by the institutional statuses invoked by the interaction. The defendant's behaviour is not clearly embedded under the CO and D object. We now want to pursue the argument that it is because the defendant cannot produce an answer to the enriched notion of 'value' that this courtroom interaction continues to go awry. The judge asks on multiple further occasions how much the defendant's jewellery is worth. Her responses, which are not specific enough for the implicated notion of 'value', are not treated as a lack of access to the correspondence between their statuses as judge and defendant, but rather are treated by the judge as indexing a status which is not appropriate to the courtroom setting. The following two representations aim to capture the judge's interpretants as highlighting the relationship between the defendant's behaviour and the judge's inference of her subprehension and what this suggests in terms of the status she indexes. We have removed large parts of the dialogue and we advise readers to look through the transcript in its entirety. The point we are stressing is that because the defendant's response of "I own a lot of jewellery" is not treated as an appropriate acceptance phase within the courtroom project, it is never concluded. Therefore, everything that follows the defendant's response to the court official's question is sequentially related to her response. Ultimately, this is what the judge is trying to ascertain. The judge's responses can be analyzed according to the statuses that his interpretants suggest are being enacted. Both are presented together:

Judge and club-goer( agency(what do you own?, I own a lot of jewellery, alright), agency(I own a lot of jewellery, alright, [...] we are not in a club.)

)

Judge and drug taker(

agency(what do you own?, I own a lot of jewellery, alright), agency(I own a lot of jewellery, alright, [...] have you had any kind of drugs in the in the last 24 hours?) 
)

In the first of these two representations, the judge is treating the defendant's inability to answer the question as indicative of the fact that she is not enacting the status of defendant, but of club-goer or of someone enacting behaviour consistent with someone with diminished control due to taking drugs. But why is this important? It is our contention that it is important because it highlights that there is an expectation that the defendant will be able to behave in accordance with her status in the courtroom. In other words, she should behave in accordance with the model:

agency(defendant, behaviour)

As described above, this representation is supposed to show that the defendant will act in a certain way because she is a defendant. However, behaving in such a way requires knowledge of the type of behaviour consistent with the status of defendant. We know from the recording that this particular defendant has no priors and is very unlikely to have previously been in a courtroom in the capacity of defendant. Therefore, the model we should adopt to analyze her behaviour is:

$$
\text { agency(behaviour, defendant) }
$$

This representation shows that her status as defendant is emergent in her behaviour and since she does not have knowledge of defendant as a type, she cannot be expected to operate in accordance with it. However, what we can see from the judge's evaluations is that he interprets her behaviour differently. These can be represented as:

$$
\begin{aligned}
& \text { agency(club-goer, behaviour) or } \\
& \text { agency(drug-taker, behaviour) }
\end{aligned}
$$

Further evidence for this can be found in a final example (lines 120-132):

$\mathrm{m} \quad\left[>\mathrm{I}^{\prime}\right.$ ll accept $<$ appoint.ment at this
$\mathrm{t}[\mathrm{ime}$ 
j $\quad[$ no. no $=\mathrm{I}>$ ain't going to $<$ appoint? you. because you're also not on my- substantial amounts of jewel.lery.

j you can go and sell your jew:ellery.

j je:well::ery for a (0.6) private, attorney.=

In this sequence the judge is stating that he cannot appoint the court official (i.e., provide the defendant with pre-trial services) because the defendant has suggested that she owns "substantial amounts of jewellery". Therefore, since the significance of the judge's turn is based on the fact that the defendant referred to jewellery earlier in the interaction, we can semiotically represent this sequence as:

Judge and defendant(

agency(what do you own?, I own a lot of jewellery, alright), agency(I own a lot of jewellery, alright, [...] no I ain’t going to appoint you. Because substantial amounts of jewellery.) )

Part of the issue here is that while the judge has on several occasions treated the defendant's behaviour as being inappropriate for a courtroom setting, he is ultimately treating its representational content as being fitted to the question of "what do you own?". There is an inconsistency here. The defendant is not behaving as a defendant residentially (performing roles and identities), but the representational content (the propositional meaning) behind what she has said is being treated as being produced as if she were able to make the inference required to understand the contextual meaning of 'value'.

What this all suggests is that the judge is treating the defendant's inappropriate behaviour (not answering the question) as a sign, which was produced as embedded under the status of defendant, but without properly subprehending the interpretants that might result from its production. In other words, the defendant is intentionally behaving in a way that is inappropriate in not answering the question for the court. However, our analysis has 
highlighted that through analyzing linguistic tokens and their correspondences, there is a clearer explanation. By treating the defendant's inappropriate turn as an interpretant, which was produced without full access to the normative practices associated with the status of defendant, we argue that the defendant does not have access to the enrichment of 'value'. Therefore, she is unable to answer the question appropriately in a court setting. The defendant is not deliberately acting under some other status, but is trying to establish how she should be behaving in accordance to the status she does not have access to (see O'Driscoll [this issue] for an analysis which shows how the defendant is led astray).

We believe that the situation could have been avoided if, instead of assuming a nonappropriate status as being the origin of the defendant's behaviour, the judge and the court official explained (i) what is expected of the defendant in this setting, and (ii) explicated what is meant by 'value' in this legal sense. It is because of a lack of a priori knowledge relating to the status of defendant that there is a breakdown in this interaction.

\section{Conclusion}

What we have shown in this analysis is that a neo-Peircean approach to interaction affords analysts the ability to analyze data from different perspectives. In doing so, what we hope to have achieved is an analysis that unlike some previous studies in politeness theory that necessarily rely on the analyst's interpretation of the interaction after the fact, can be replicated to come to the same analytic conclusions, and reapplied to other interactions. Further, it can be adopted across different types of analysis used in politeness research, e.g., CA, Relevance Theory.

Neo-Peircean semiotics is a relatively new approach within interaction studies and the application of it is certainly new within politeness analyses. We have shown, in line with 
Enfield (2013) that it facilitates the analysis of a broad range of interactionally salient phenomena from individual linguistic tokens to culturally bounded phenomena such as courtroom norms. Moreover, it allows the politeness theorist a systematic and transferable framework with which to analyze these different levels, showing how they are interrelated and causally linked by being able to selectively focus on different parts of the interaction.

What this paper has also shown is the real-world applications that linguistic analyses can have. In line with work done in other areas of linguistics, such as sociolinguistics (Rickford and King, 2016) and forensic linguistics (Bhatia, 2010), not having access to the norms of the courtroom or knowing how to interpret legal discourse can have serious implications for the outcomes of the trial and whether the people involved are taken seriously. Moreover, it raises a question of whose responsibility it is to make sure that defendants (and witnesses in the case discussed by Rickford and King) know what is expected of them in a legal context. This is the crux of the issue in the Soto case as evidenced through our analysis - the defendant simply does not know what is expected of her and the court officials neglect to convey this information to her. It is only through breaking down the interaction that this becomes clear.

\section{References}

Archer, Dawn \& Cliff Lansley. 2015. Public appeals, news interviews and crocodile tears: an argument for multi-channel analysis. Corpora, 10(2). 231-258.

Arundale, Robert B. 2010. Constituting face in conversation: Face, facework, and interactional achievement. Journal of Pragmatics, 42(8). 2078-2105.

Austin, John L. 1962. How to do Things with Words. The William James lectures delivered at Harvard University in 1955. Oxford: Clarendon Press. 
Bavelas, Janet, Peter De Jong, Harry Korman \& and Sara. S. Jordan. 2012. Beyond backchannels: A three-step model of grounding in face-to-face dialogue. In Proceedings of Interdisciplinary Workshop on Feedback Behaviors in Dialog, Stevenson, WA, USA September 7-8. 5-6.

Bhatia, Vijay. K. 2010. Legal writing: Specificity. Specification in legal writing: Accessibility, transparency, power and control, in: Malcolm Coulthard \& Alison Johnson (eds.), The Routledge handbook of forensic linguistics. 21-37. London: Routledge.

Bom, Isabelle van der \& Karen Grainger 2015. Journal of politeness research: Introduction. Journal of Politeness Research, 11(2).165-178.

Brown, Penelope \& Stephen C. Levinson. 1987. Politeness: Some Universals in Language Usage. Cambridge: Cambridge University Press.

Carston, Robyn. 2002. Thoughts and utterances: The pragmatics of explicit communication. New York: Wiley.

Christie, Christine. (this issue) The indexical scope of adios: a relevance theoretic analysis of discursive constructions of gender and institutions and their impact on utterance interpretation.

Clark, Herbert H. 1996. Using language. Cambridge: Cambridge University Press.

Clark, Herbert H. \& Meredyth A. Krych. 2004. Speaking while monitoring addressees for understanding. Journal of Memory and Language, 50(1).62-81.

Ekman, Paul. 1999. Emotional and conversational nonverbal signals. In Lynn S. Messing \& Ruth Campbell. (eds.), Gesture, Speech, and Sign, pp. 45-55. Oxford: Oxford University Press. 
Enfield, Nick. J. 2009. Relationship thinking and human pragmatics. Journal of Pragmatics, 41(1). 60-78.

Enfield, Nick., J. 2013. A ‘composite utterances’ approach to meaning. In Cornelia Müller, Ellen Fricke, Silva H. Ladewig, Alan Cienki, David McNeill, \& Sedinha Teßendorf. (eds.) Handbook of Body - Language-Communication. volume 1. Berlin: Mouton de Gruyter.

Goffman, Erving. 1967. Interaction Ritual. New York: Pantheon.

Grainger, Karen. 2011. First order 'and 'second order 'politeness: Institutional and intercultural contexts. In Linguistic Politeness Research Group (ed.), Discursive approaches to politeness. 167-188. Berlin and Boston: De Gruyter Mouton.

Grice, H. Paul. 1957. Meaning. The philosophical review. 66(3). 377-388.

Grice, H. Paul. 1975. Logic and conversation. In Peter Cole \& Jerry Morgan (eds.) Syntax and Semantics 3: Speech Acts. 41-58. New York: Academic Press.

Haugh, Michael. 2007. The discursive challenge to politeness theory: an interactional alternative. Journal of Politeness Research, 3(2). 295-317.

Hutchby, Ian. \& Robin Wooffitt 2008. Conversation analysis. Cambridge: Polity.

Jackendoff, Ray. 2007. Language, consciousness, culture: Essays on mental structure. Cambridge MA: MIT Press.

Kockelman, Paul. 2005. The semiotic stance. Semiotica, 2005(157). 233-304.

Kockelman, Paul. 2006a. Representations of the world: Memories, perceptions, beliefs, intentions, and plans. Semiotica. 2006(162). 73-125.

Kockelman, Paul. 2006b. Residence in the world: Affordances, instruments, actions, roles, and identities. Semiotica. 2006(162). 19-71. 
Kockelman, Paul. 2007. Agency. Current Anthropology. 48(3). 375-401.

Kockelman, Paul. 2012. Meaning, motivation, and mind: Some conditions and consequences for the flexibility and intersubjectivity of cognitive processes. New Ideas in Psychology, 30(1). 65-85.

Levinson, Stephen. C. 1979. Activity types and language. Linguistics, 17(5-6). 365-400.

Linton, Ralph. 1936. The Study of Man: An Introduction. New York: Appleton-CenturyCrofts.

Locher, Miriam A. \& Richard J. Watts. 2005. Politeness theory and relational work. Journal of Politeness Research. 1(1). 9-33.

McIntyre, Dan. \& Derek Bousfield 2017. (im)politeness in fictional texts. In Jonathan Culpeper, Michael Haugh, \& Daniel Z. Kádár,. (eds.). The Palgrave Handbook of Linguistic (Im)politeness. 759-783. London: Springer.

Meier, Ardith J. 1995. Passages of politeness. Journal of Pragmatics, 24(4). 381-392.

O’Driscoll, Jim. (this issue) Dances with footings: a Goffmanian perspective on the Soto case

Ochs, Elinor. 1996. Linguistic Resources for Socializing Humanity. In John Gumperz \& Stephen Levinson (eds.), Rethinking linguistic relativity. 407-438. Cambridge: Cambridge University Press

Parret, Herman. 1984. Peirce and Hjelmslev: The two semiotics. Language Sciences. 6(2). $217-227$.

Peirce, Charles Sanders.. 1955. Philosophical Writings of Peirce. New York: Dover Publications.

Pomerantz, Anita. 1984. Agreeing and disagreeing with assessments: Some features of preferred/dispreferred turn shapes. In J. Maxwell Atkinson \& John Heritage. (eds.) 
Structures of Social Action: Studies in Conversation Analysis, pages 57-101.

Cambridge University Press.

Rickford, John R. \& Sharese King,. 2016. Language and linguistics on trial: Hearing Rachel Jeantel (and other vernacular speakers) in the courtroom and beyond. Language, 92(4). 948-988.

Sacks, Harvey. 1987. On the preferences for agreement and contiguity in sequences in conversation. In Graham Button \& John Lee (eds.). Talk and social organization, volume 54. 54-69. England: Multilingual Matters Ltd.

Schneider, Klaus. P. 2012. Appropriate behaviour across varieties of English. Journal of Pragmatics, 44(9). 1022-1037.

Searle, John. R. 2010. Making the social world: The structure of human civilization. Oxford: Oxford University Press.

Silverstein, Michael. 2003. Indexical order and the dialectics of sociolinguistic life. Language \& communication, 23(3).193-229.

Wilson, Deirdre \& Robyn Carston.2007. A unitary approach to lexical pragmatics:

Relevance, inference and ad hoc concepts. In Noel Burton-Roberts. (ed.). Pragmatics, 231-259 Basingstoke, Hampshire: Palgrave-Macmillan.

Jack Wilson

Jack Wilson is a lecturer in English Language at the University of Salford. His research interests include the semantics/pragmatics interface, focussing on features of face-to-face interaction, gesture, and the evolution of semiotic systems. He is currently working on 
projects investigating the role of gesture in language production and comprehension and the language and gestural practices of users of Modern Saudi Arabian Languages.

\section{Hazel Price}

Hazel Price is Research Information and Communications Officer in the Department of Linguistics and Modern Languages at the University of Huddersfield. Her research interests include pragmatics, corpus linguistics and critical discourse analysis. She is Editorial Assistant for Babel: The Language Magazine (www.babelzine.com) and co-editor of Applying Linguistics: Language and the Impact Agenda (Routledge, 2018) 